\title{
Process Chain Modelling and Analysis for the High-Volume Production of Thermoplastic Composites with Embedded Piezoceramic Modules
}

\author{
W. Hufenbach, M. Gude, N. Modler, Th. Heber, A. Winkler, and T. Weber \\ Technische Universität Dresden, Institute of Lightweight Engineering and Polymer Technology (ILK), \\ Holbeinstraße 3, 01307 Dresden, Germany \\ Correspondence should be addressed to A. Winkler; aw@ilk.mw.tu-dresden.de
}

Received 5 October 2012; Revised 14 January 2013; Accepted 25 February 2013

Academic Editor: Marcelo J. Dapino

Copyright (C) 2013 W. Hufenbach et al. This is an open access article distributed under the Creative Commons Attribution License, which permits unrestricted use, distribution, and reproduction in any medium, provided the original work is properly cited.

\begin{abstract}
Active composite structures based on thermoplastic matrix systems are highly suited to applications in lightweight structures ready for series production. The integration of additional functional components such as material-embedded piezoceramic actuators and sensors and an electronic network facilitates the targeted control and manipulation of structural behaviour. The current delay in the widespread application of such adaptive structures is primarily attributable to a lack of appropriate manufacturing technologies. It is against this backdrop that this paper contributes to the development of a novel manufacturing process chain characterized by robustness and efficiency and based on hot-pressing techniques tailored to specific materials and actuators. Special consideration is given to detailed process chain modelling and analysis focusing on interactions between technical and technological aspects. The development of a continuous process chain by means of the analysis of parameter influences is described. In conclusion, the use of parameter manipulation to successfully realize a unique manufacturing line designed for the high-volume production of adaptive thermoplastic composite structures is demonstrated.
\end{abstract}

\section{Introduction}

The increasing scarcity or resources around the world necessitates the development of high-tech products with a high level of sustainability. Function-integrative lightweight engineering in multimaterial design is a vital source of key technologies for various applications in this field. In recent years comfort and environmental criteria have become an increasingly important element of automotive, medical, and civil engineering applications. The superior specific mechanical properties, excellent design flexibility, and cost-efficient, reproducible manufacturing processes which characterize fibre-reinforced composites based on thermoplastic matrix systems enable them to fulfil these criteria. In particular, those characteristics make them highly suited to applications in lightweight structures ready for high-volume production. Moreover, the integration of additional functional components such as piezoceramic actuators or sensors into thermoplastic lightweight structures facilitates the manipulation of the dynamic and vibroacoustic behaviour of those structures [1-3]. In addition to quality monitoring, energy harvesting, and active vibration or noise control [4-8], a number of structural applications (e.g., in morphing structures and compliant mechanisms) are also possible [9-13].

State-of-the-art production of adaptive lightweight components is predominantly characterized by the separate manufacturing of the composite structure and functional piezoceramic modules, which is accompanied and followed by a considerable number of bonding processes [14-16]. The adhesive bonding of the functional module to the composite structure is required, and the adhesive film applied between the module and the fibre-reinforced polymer structure leads to a loss in deformation transfer. Sensor and actuator potential is therefore used inefficiently [17]. The rising number of potential applications in several fields involving highvolume production (e.g., the automotive industry) necessitates the robust, high-volume production of intelligent lightweight structures. A transition from assembly-oriented 


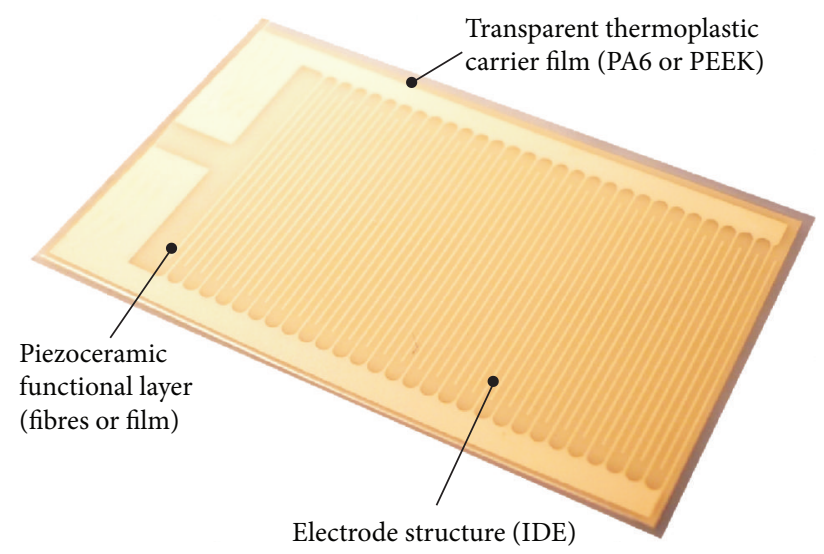

FIGURE 1: Prototypic, thermoplastic-compatible piezoceramic module.

to technology-oriented actuator manufacturing and integration is therefore necessary [18-20]. It is with this in mind that novel piezoceramic modules specifically tailored to fibrereinforced thermoplastic composites [18] have been designed (Figure 1).

Known as "thermoplastic-compatible piezoceramic modules" (TPMs), the modules exhibit actuation properties which are comparable to those of equivalent thermoset-based macrofibre composites (MFC) [18]. The embedding of TPMs into thermoplastic-based composites leads to improved deformation transfer when compared with bonded MFC. The TPMs are directly embedded into the composite structure and positioned even closer to both the reinforcement and the neutral fibre. This results in enhanced utilization of deformation potential.

In addition to the development of the TPMs a continuous, automated process chain for active components with embedded TPMs is also necessary. Detailed process chain modelling and analysis is therefore required in order to ensure reproducible, robust manufacturing. As a result the manifold influences of the various parameters involved (e.g., those related to the material, component geometry, and the technology used) and reciprocal interactions between them need to be considered.

\section{Process Chain Conceptualization}

Process chain modelling and analysis was preceded by the design of a process chain concept. That concept was primarily informed by previous numerical and experimental sensitivity analyses of the individual process steps involved [18-21].

The process chain starts with TPM manufacturing, which comprises electrode application, TPM assembly and conversion, and TPM consolidation. The resultant process is based on roll-to-roll technology (Figure 2).

The basic materials for the process are two thermoplastic film webs, conductive material for electrode application, and various piezoceramic functional layers. The functional principle of the TPM is based on functional layers consisting of monolithic piezoceramic films or composites made of piezoceramic fibres and polymeric matrix material. Commercially available metallized monolithic wafers are used for TPMs in $\mathrm{d}_{31}$ mode, with specially developed fibre-based piezoceramic functional layers used for TPMs in $\mathrm{d}_{33}$ mode. They are currently made of PZT fibres and epoxy resin [22]. One important element of the fibre composite development process is the realization of a composite with an adapted thermoplastic matrix compatible with the TPM material system.

The TPM manufacturing process starts with the application of the electrode design to the thermoplastic film. Depending on the carrier film material used, electrode application occurs by means of tailored additive or subtractive technologies such as screen printing, laminating, or etching. The functional layer is subsequently positioned on the electrode on the lower web and covered with an upper thermoplastic film web featuring applied electrode structures. Both film webs have to be precisely positioned if congruent alignment between the upper and lower electrode structures is to be achieved. The aligned components are then fixed with the aid of a thermal welding step and stamped as converted TPMs. The final step sees the TPM consolidated using a tailored hot-pressing technique.

The next process involves the contacting of the TPMs in order to ensure the electrical actuation of the modules. A special laser contacting technology based on a solder ball bumper system is used [23]. The process is followed by the manufacturing of the active components. This sees consolidated and contacted TPMs embedded into a composite structure by means of a film-stacking process. The filmstacking lay-up has to be prepared prior to consolidation, and this starts with the equipment of a thermoplastic film with contacted TPMs. This so-called "e-preforming process" comprises the precise positioning of the TPMs, the application of conductive paths to the TPMs, and the contacting and fixation of the TPMs to the thermoplastic carrier film using a thermal or ultrasonic welding technique (Figure 3). The final step sees the thermoplastic film-which now features fixed conductors and contacted TPMs - cut into defined sections or "e-preforms."

The thermoplastic films equipped with contacted TPMs are subsequently transferred to a material store where they are dried if necessary. A robotic handling system is then used to place the dried e-preform into the pressing die. The robot then stacks an individual lay-up consisting of fibrereinforced thermoplastic preforms and individual thermoplastic composite layers with the aid of a tailored handling device (or so-called "picker/stacking tool"; see Figure 4). Subsequent processing steps see the composite lay-up fixed and transferred by the robot featured within this device. After the composite lay-up has been assembled, the picker/stacking tool is transferred to a preheating station. Immediately after the melting of the thermoplastic matrix material, the layup is transferred to the hot-pressing unit, where the epreform and the preheated lay-up are combined to form an active structural component. Pressing parameters (e.g., process temperature, time, and pressure) must be precisely adjusted if the proper consolidation of the composite is to 


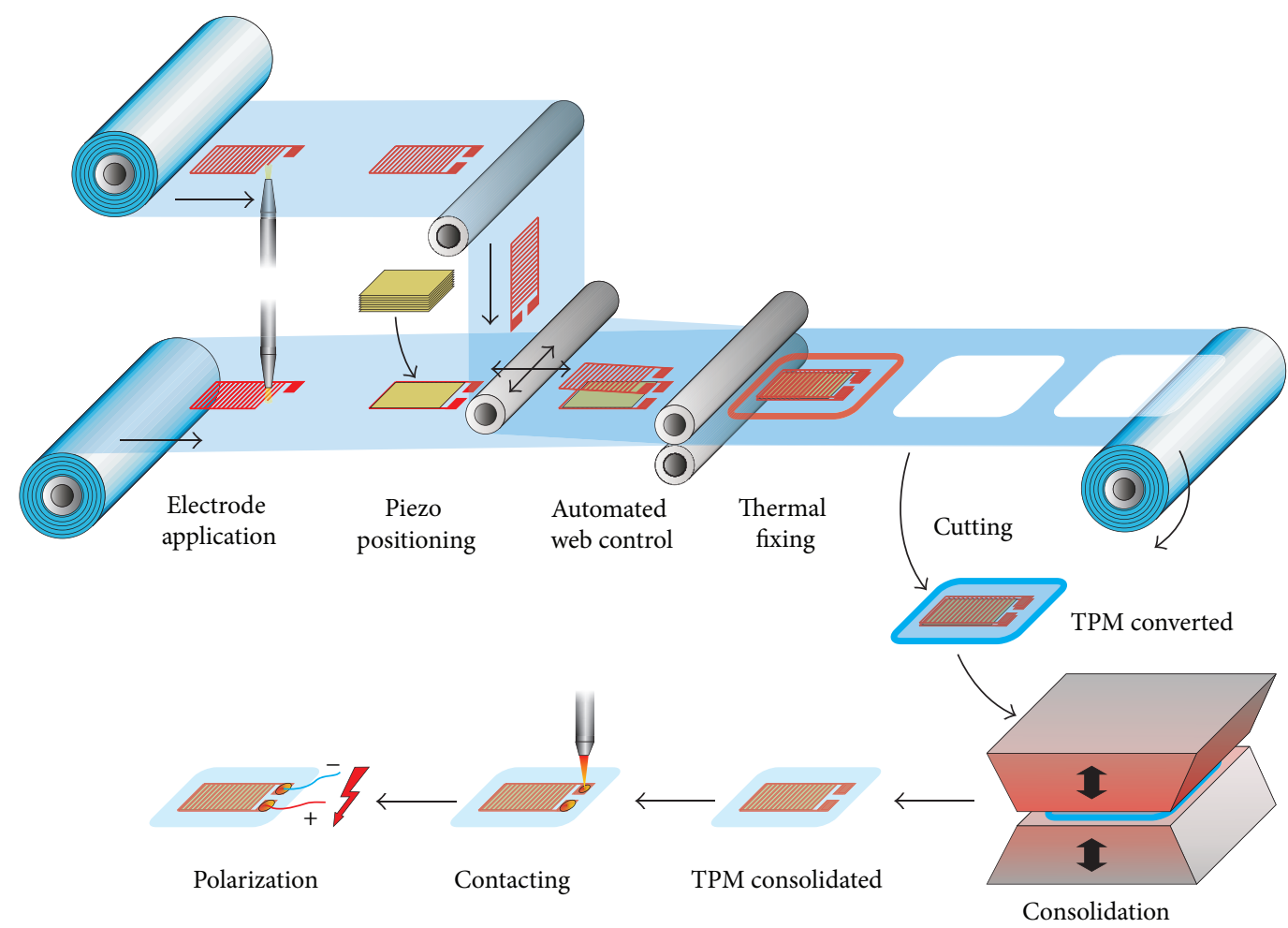

FIGURE 2: Schematic diagram of the TPM manufacturing process.

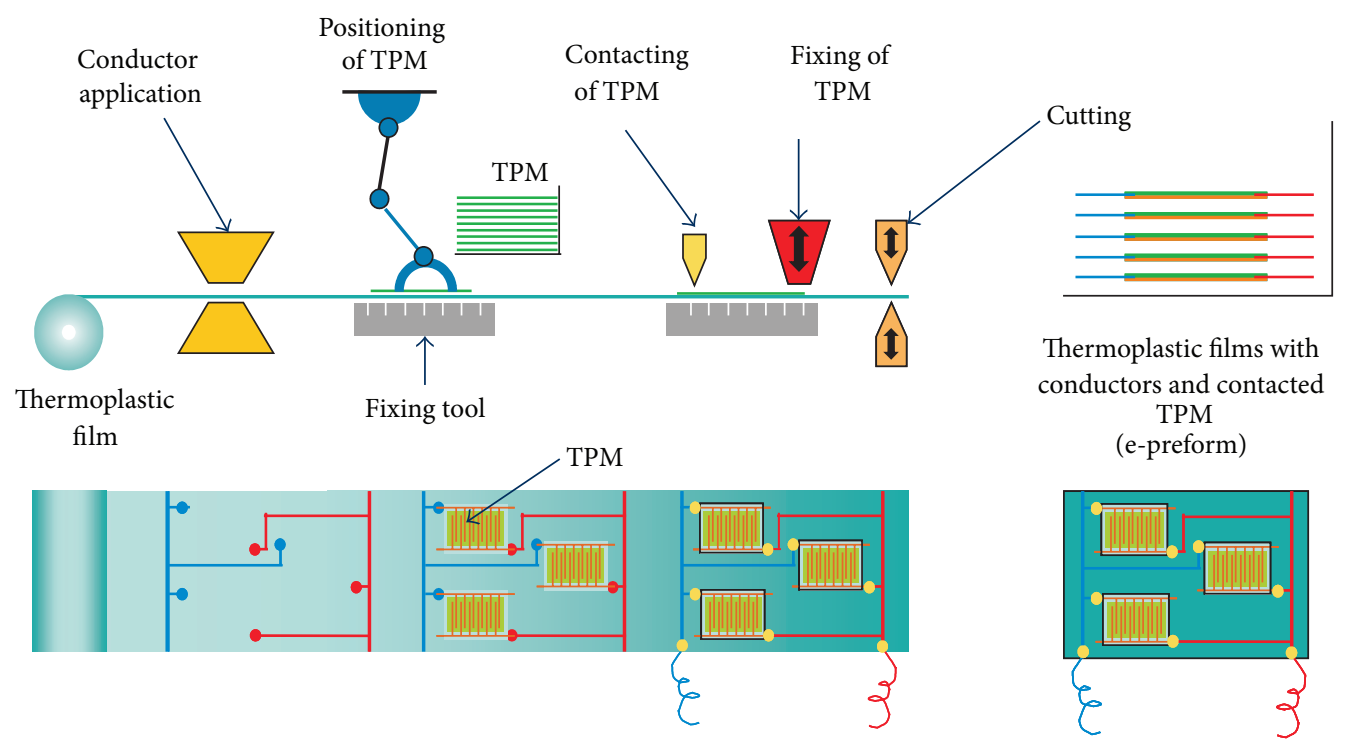

FIGURE 3: Schematic diagram of the e-preforming process.

be ensured without causing damage to the TPMs. During the consolidation process, the simultaneous online polarization of the embedded TPM brings about the switch from a passive to an active composite. Thermomechanical processing conditions are adjusted in a targeted manner in order to achieve a highly efficient polarization process.

\section{Process Chain Modelling and Analysis}

The automated, robust and efficient manufacturing of thermoplastic composites with embedded piezoceramic modules necessitates the modelling of an integrated process chain. Interactions between process steps, manufacturing 


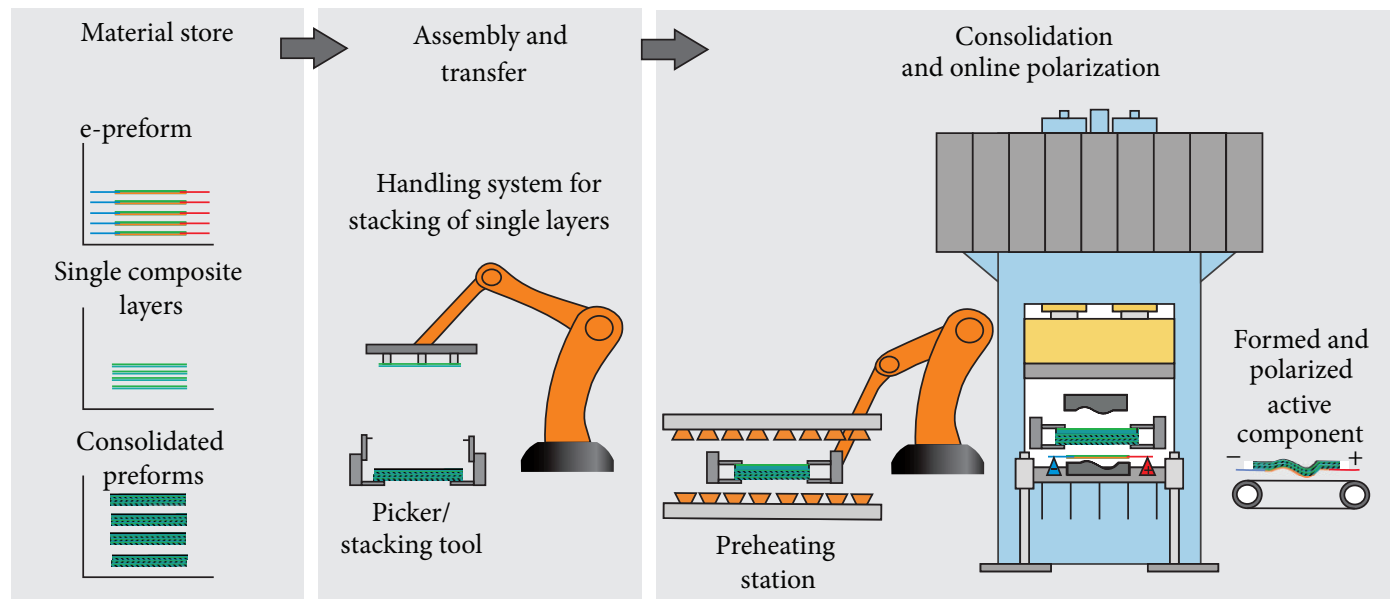

FIGURE 4: Schematic diagram of the process steps used to produce an active composite component.

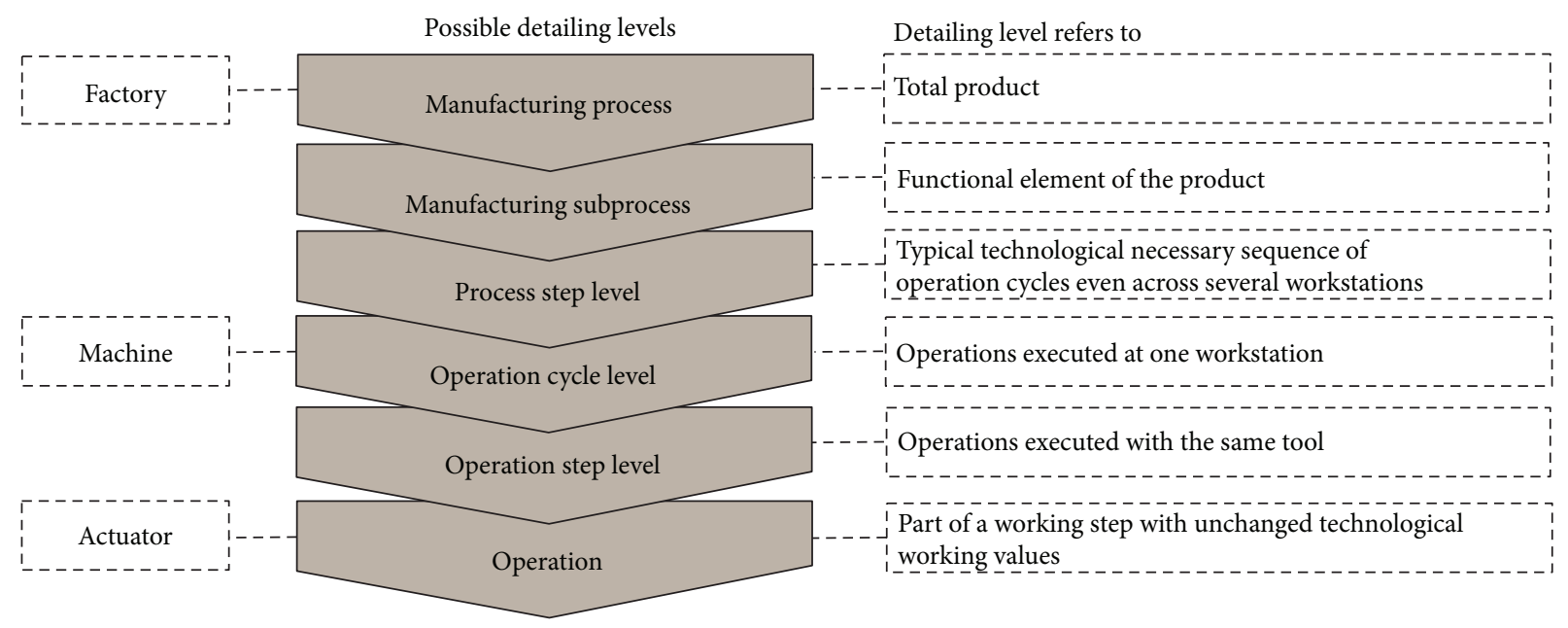

FIGURE 5: Hierarchical levels for the vertical detailing of the process structure [24].

equipment, manufacturing principles, and the materials and components processed are all to be taken into consideration. The resultant process chain model is to provide a basis for the exhaustive analysis and targeted adaptation of variable process parameters. The methodology described in [24] states that the objects of constitutional changes, constitutional changes themselves, and dedicated devices allocated to underlying manufacturing processes are to be identified and arranged in an appropriate sequence. The resultant horizontal process chain model is to be successively analysed by means of the vertical detailing of the individual process steps down to the required itemization level (see Figure 5).

Vertical detailing starts with the integrated manufacturing process, which is broken down into manufacturing subprocesses, process step levels, operation cycle levels, and operation step levels. Influencing factors, parameters, and technical-technological interactions can be systematically examined and evaluated on each level. The input data used for the integrated analysis of the process chain is based on previous experimental and numerical parametrical studies dealing with individual process steps.

The comprehensive horizontal model of the entire process chain comprises the following objects of constitutional change: input material, TPM, e-preform, and active component. The corresponding constitutional changes are therefore TPM manufacturing, e-preforming, and composite component manufacturing (Figure 6).

The constitutional changes correspond with the three fundamental subprocesses, each of which can be independently monitored, described, and analysed. Vertical classification into various levels facilitates the integrated representation of the process chain and provides a basis for detailed process chain analysis as shown in Figure 7.

3.1. TPM Manufacturing. The TPM manufacturing process is divided into the following subprocesses: manufacturing of the piezoceramic functional element (wafer); electrode application; TPM assembly and conversion; TPM consolidation; 


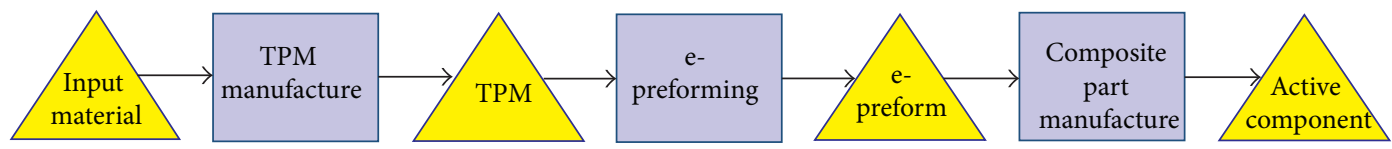

FIGURE 6: Comprehensive horizontal process chain model.

Comprehensive manufacturing process

Manufacturing of active fibre-reinforced thermoplastic components with embedded TPMs

Subprocesses

TPM manufacturing

(A)

Process step level

\begin{tabular}{|c|c|c|c|c|c|c|c|}
\hline $\begin{array}{c}\text { Wafer } \\
\text { manu- } \\
\text { facturing }\end{array}$ & $\begin{array}{l}\text { Assembly } \\
\text { and } \\
\text { conversion }\end{array}$ & $\begin{array}{l}\text { Consoli- } \\
\text { dation }\end{array}$ & $\begin{array}{l}\text { Definition } \\
\text { and film } \\
\text { supply }\end{array}$ & $\begin{array}{l}\text { TPM } \\
\text { appli- } \\
\text { cation }\end{array}$ & $\begin{array}{l}\text { Conductor } \\
\text { appli- } \\
\text { cation }\end{array}$ & Lay-up & $\begin{array}{l}\text { Hot pressing } \\
\text { and online } \\
\text { polarization }\end{array}$ \\
\hline A.1 & А.L & & & B. 2 & B. 3 & C.I & C. 2 \\
\hline
\end{tabular}

Operation cycle level

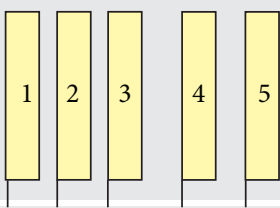

Operation step level

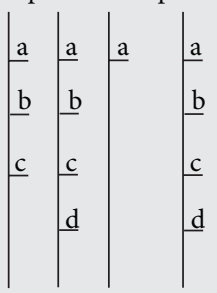

a

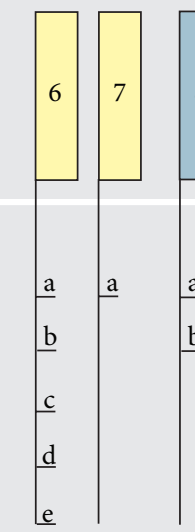

(1) Fibre block preform manufacture
(a) Material drying
(b) Material assembling
(c) Completion of the infiltration tool

(2) Consolidation

(a) Assembling the laboratory press

(b) Heating

(c) Hot pressing and cooling

(d) Removal of the fibre block preform

(3) Finishing

(a) Cut to size by sawing

(4) Assembly and conversion

(a) Assembling of the film with PZT fibre preform

(b) Automatic web positioning

(c) Thermal fixation

(d) Punching to module size

(5) Contacting (in research)

(6) Consolidation

(a) Drying of the TPM

(b) Lay-up in laboratory press

(c) Heating
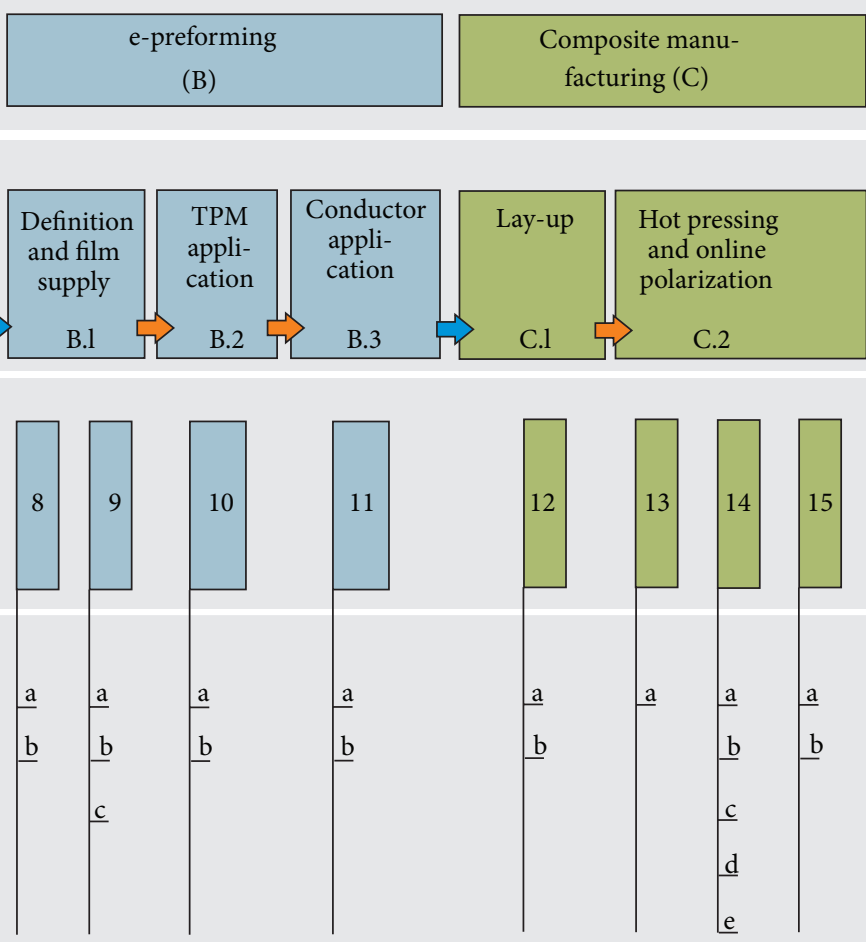

(d) Hot pressing and cooling

(e) Removal of the TPM from

(7) Finishing

(a) Cutting the TPM to nominal dimensions

(8) Definition

(a) Definition of TPM

(b) Definition of the conductor layout

(9) Film supply

(a) Supplying the film

(b) Cutting the film

(c) Positioning and fixing of the film

(10) TPM application

(a) TPM positioning

(b) TPM fixation

(11) Conductor application

(a) Conductor supply

(b) Conductor fixation

(b) Transport and stapling of the cover layers in the stapling tool

(13) Transfer and positioning

(a) Transferring the e-preform into the press

(14) Hot pressing and onlinepolarization

(a) Preheating

(b) Positioning of the lay-up in the pressing die

(c) Hot pressing

(d) Cooling and online polarization

(e) Removal of the stapling tool

(15) Finishing

(a) Removal of the component from the stapling tool

(b) Deburring of the component edges laboratory press

FIGURE 7: Comprehensive process chain model with vertical levels. 


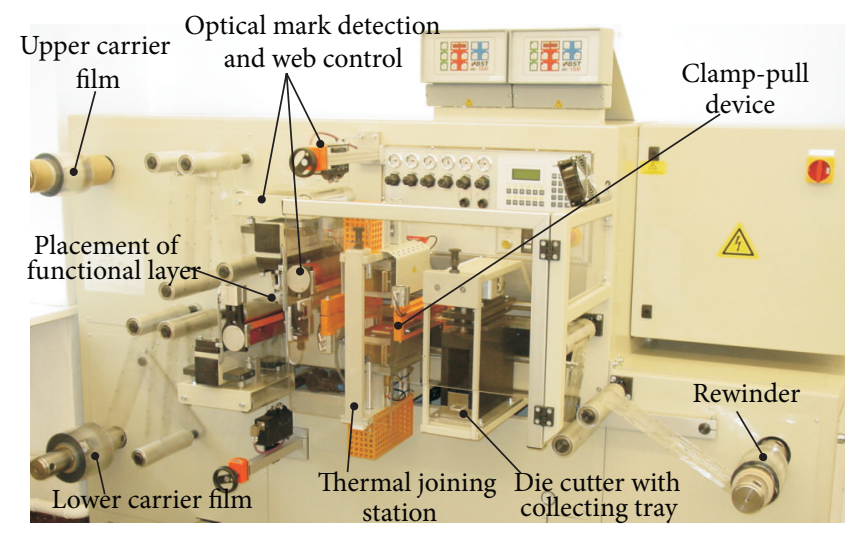

FIgURE 8: TPM assembly and conversion device.

TPM contacting. An individual subprocess (TPM assembly and conversion) is broken down and examined here in order to gain an insight into the modelling and analysis of the process chain.

The automated TPM assembly and conversion device (Figure 8) was designed and installed in accordance with the overall process chain concept and with the aid of fundamental parametrical studies. The device is based on roll-to-roll technology which sees film webs unwound before being coiled up further again to various intermediate processing steps.

The first step is the positioning of the functional layers already produced on the electrode structure of the lower carrier film web. An upper carrier film web prepared in the same way is then precisely aligned with the electrode structure of the lower web. This process is supported by the detection of positioning marks using optical measurement systems. The combined lay-up consisting of the lower web, functional layer, and upper web is subsequently partially fixed in a thermal joining station and stamped using a die cutter. The assembled and converted TPM is now ready for further processing in the subsequent TPM consolidation process. The main machine parameters of the TPM assembly and conversion device are appropriate for examination in this paper and listed in Table 1 .

Extensive sensitivity analyses of these machine parameters have been carried out using polyamide 6 (PA6) carrier films with a thickness of $100 \mu \mathrm{m}$ and lead zirconate titanate (PZT) wafers (functional layer) with a thickness of $200 \mu \mathrm{m}$. The carrier film webs were first equipped with silver electrodes at an interval of $70 \mathrm{~mm}$ using screen printing technology [18]. The web feed rate therefore needed to be adapted to the repeating pattern. The pressure, temperature, and exposure time within the thermal joining station remain in permanent interaction and can therefore not be considered independently. Joining station temperature was nevertheless identified as the primary influence on the quality of TPM conversion. It was also observed that the adjustable parameters of the automated web control system and the accuracy of the printed patterns used for the purposes of optical detection can cause electrode misalignment between the upper and
TABLE 1: Adjustable machine parameters of the TPM assembly and conversion device.

\begin{tabular}{lcc}
\hline Parameter & $\begin{array}{c}\text { Adjustment } \\
\text { range }\end{array}$ & Step size \\
\hline Feed rate/repeating pattern $(\mathrm{mm})$ & 45 to 170 & 0.1 \\
Joining station temperature $($ top $)\left({ }^{\circ} \mathrm{C}\right)$ & $\leq 400$ & 1 \\
Joining station temperature (bottom) $\left({ }^{\circ} \mathrm{C}\right)$ & $\leq 400$ & 1 \\
Joining station machine pressure $(\mathrm{bar})$ & 0 to 6 & 0.05 \\
Joining station exposure time $(\mathrm{s})$ & 100 to 99,999 & 1 \\
Longitudinal web control (top) $(\mathrm{mm})$ & 0 to 40 & 0.01 \\
Longitudinal web control (bottom) $(\mathrm{mm})$ & 0 to 20 & 0.01 \\
Perpendicular web control (top) $(\mathrm{mm})$ & 0 to 320 & 0.005 \\
Perpendicular web control (bottom) $(\mathrm{mm})$ & 0 to 320 & 0.005 \\
\hline
\end{tabular}

lower electrode structures. Such misalignment can lead to a loss in performance and short-circuits and is therefore to be avoided. The studies carried out show that the device achieves positioning accuracy of $\pm 200 \mu \mathrm{m}$ (web direction) and $\pm 20 \mu \mathrm{m}$ (perpendicular to web direction), respectively, which is sufficient for high-quality, high-performance TPMs [18].

The corresponding process chain model was developed parallel to experimental investigations. It facilitates not only a profound understanding of the process chain and its subprocesses, but also the deduction of specific interactions. Figure 9 shows the process chain model subdivided into the process step level, the more detailed operation cycle level, and the itemized operation step level. The process step level includes the objects of constitutional changes and the constitutional changes themselves, whilst the operation cycle level breaks the process down to show the dedicated devices.

The individual elements of the process step level are visualized in the detailed operation cycle level included below (Figure 10). The sum of the elements on the operation cycle level and their relationship with one another describes the internal technical-technological interactions that occur. As identified in previous investigations, fixing temperature and electrode misalignment in combination with the materials 

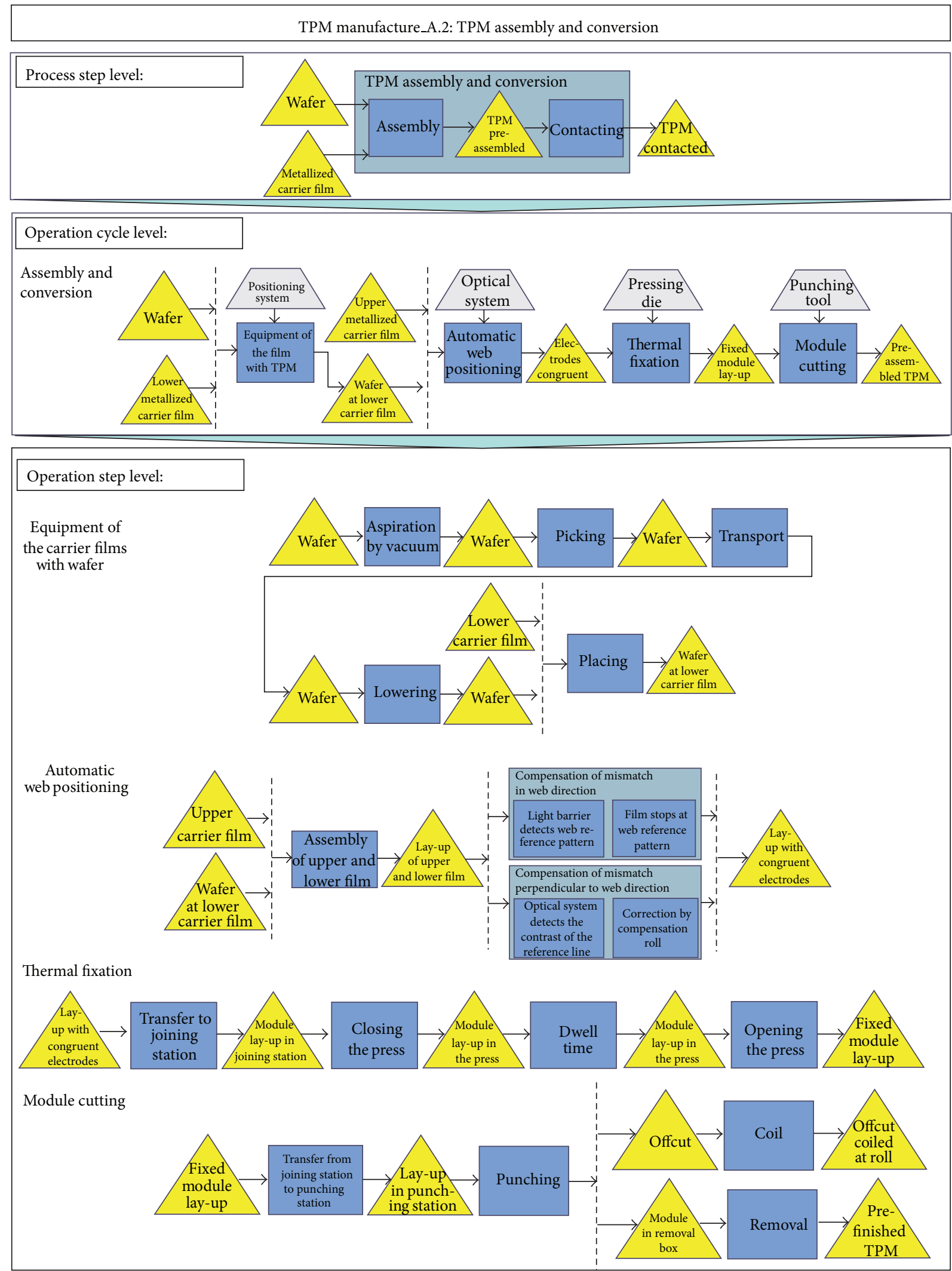

FIGURE 9: Process chain model for TPM assembly and conversion. 


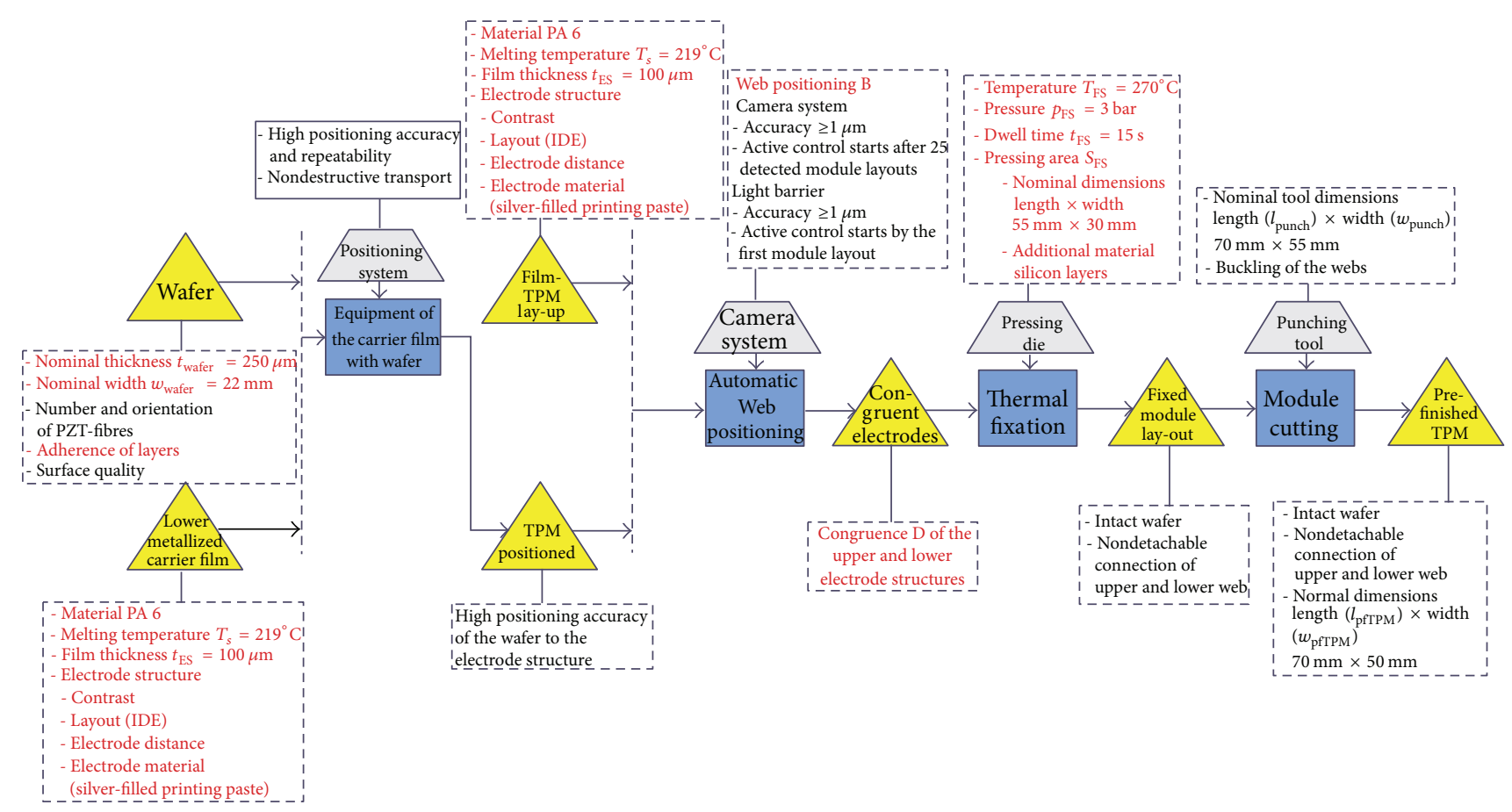

FIGURE 10: Detailed operation cycle level for TPM assembly and conversion.

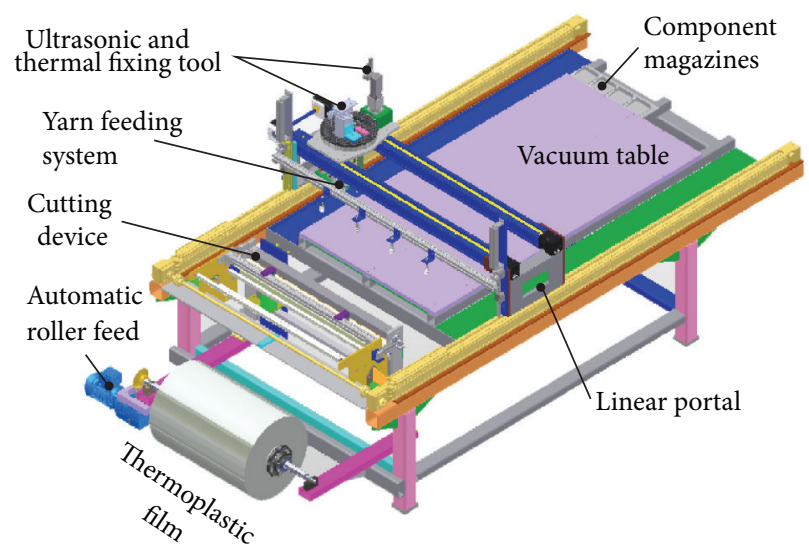

FIGURE 11: Automated e-preforming device.

used are of key importance to TPM quality. Current studies are based on the process chain models developed and interactions analysed to date and focus on the collection of more detailed and comprehensive process data. The aim in the future is to use sound statistical data acquisition techniques to illustrate and analyse specific technical-technological interactions.

3.2. e-Preforming. The consolidation and contacting of the converted TPM are followed by the next part of the overall process chain, e-preforming. This process comprises the feeding of the thermoplastic film, the application of the TPM, and the application of conductive paths (cf. Figure 3). The process chain concept developed and relevant fundamental parametrical studies carried out were used as a basis for the design and building of an automated e-preforming device (Figure 11).

The subprocess modelled below (TPM application) provides an exemplary insight into the e-preforming process (Figure 12). The thermoplastic carrier film is first fixed with the aid of a vacuum table. The consolidated TPMs are then picked up from the component magazine using a vacuum gripper. An $x-y$ portal system is used to transport the vacuum-gripped modules to a predefined position. Once in position, the TPMs are fixed by means of the targeted melting of the identical thermoplastic TPM carrier films and e-preform using an ultrasonic or thermal fixing tool.

As in the case of the TPM assembly and conversion process, the technical and technological properties exhibited 

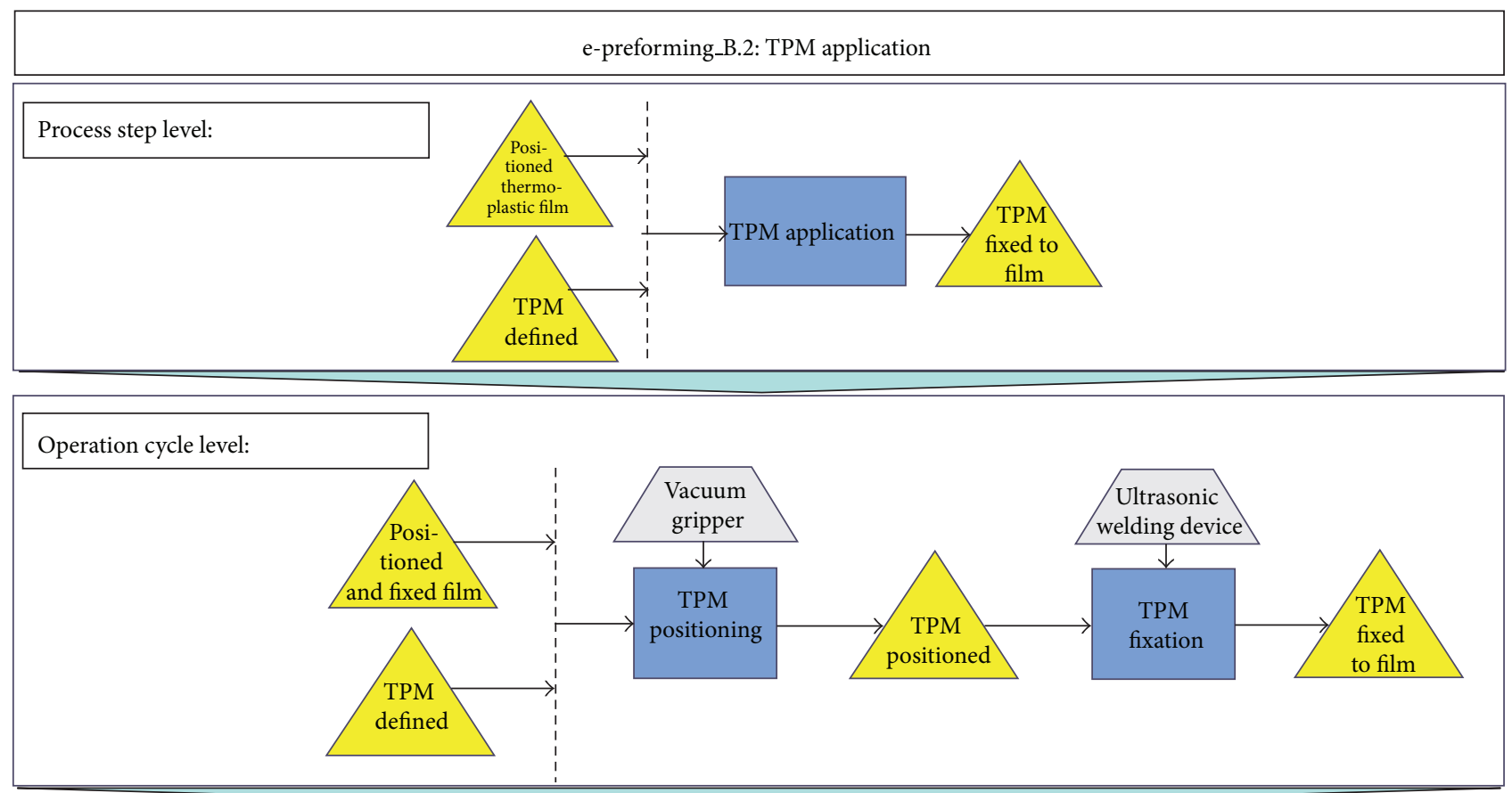

\section{Operation step level:}

TPM positioning
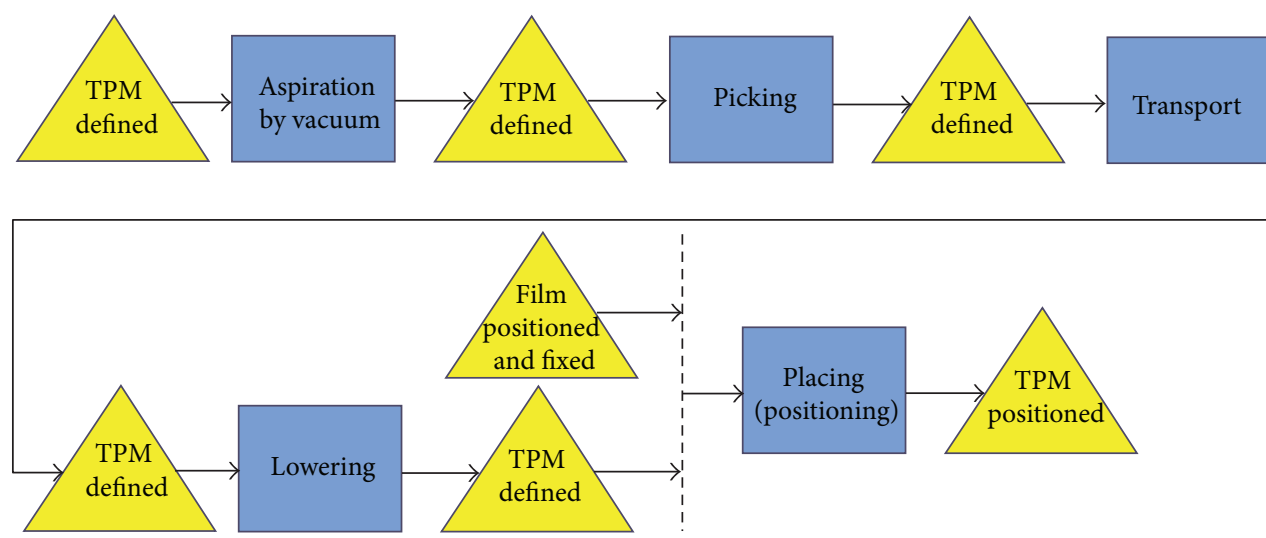

TPM fixation

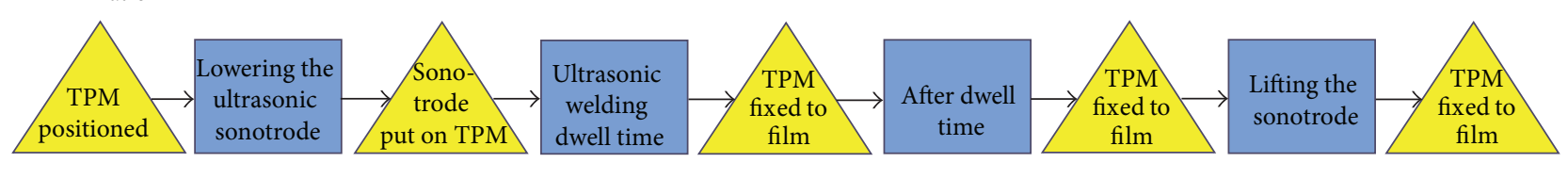

FIGURE 12: Process chain model for TPM application.

on the process step level are determined by the detailed operation cycle level. The internal interactions which promote or hinder reproducible TPM application are identified and analysed. Figure 13 illustrates the detailed operation cycle level, which includes TPM fixation with the aid of ultrasonic welding. The quality of TPM fixation primarily depends on the adjustment of three welding parameters: sonotrode pressure, exposure time, and dwell time. These parameters are to be adjusted according to external TPM characteristics such as film thickness and layer functionality.

The placement of specific TPMs in their predestined positions is followed by the application of electrical contacts to the individual TPMs. Conductive paths made of metallic wire or carbon fibre yarn are used for this purpose. The feeding and fixing of the conductive material occur on a fully automated basis with the aid of a specially developed feeding 


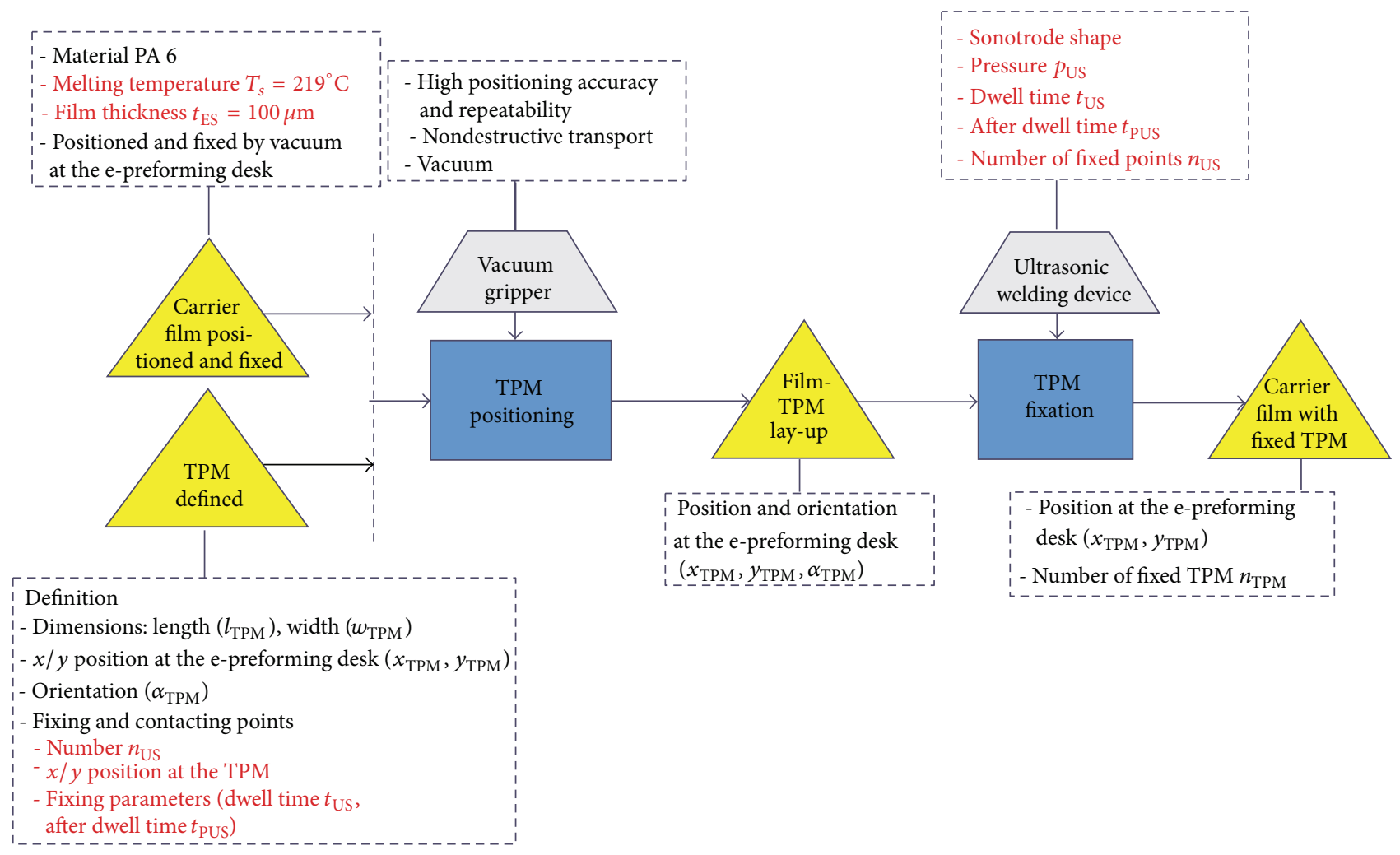

FIGURE 13: Detailed operation cycle level of TPM application.

system and a thermal stapling device. The resultant e-preform consists of TPMs and conductors on a thermoplastic carrier layer and is ready for further processing in the subprocess "composite part manufacturing."

3.3. Composite Part Manufacturing. The manufacturing of the final active composite component is divided into three process steps: lay-up, hot pressing, and online polarization. During the lay-up process, the composite laminate structure is defined and a lay-up consisting of specific composite sheets and films assembled. An automated picker/stacking tool is therefore used in combination with a robot-based handling system (cf. Figure 4). The sensitive e-preform is positioned in the pressing tool prior to the preheating of the composite lay-up with the aid of an infrared heating system. Once the preheated lay-up has also been placed into the pressing tool, the assembled laminate is consolidated together with the e-preform at relatively low pressure and high temperature. The consolidation process sees thermomechanical process conditions used to provide targeted support for the in-process polarization of the embedded piezoceramic modules [21]. Figure 14 itemizes the corresponding process chain from process step level (hot pressing and online polarization) downwards.

The following detailed operation cycle level for the hot pressing and online polarization process illustrates internal interactions (Figure 15). Red text indicates device and object properties which have a major impact on the consolidation and polarization result. The manifold potential temperature and dwell time combinations are of particular importance where the hot-pressing and polarization processes are concerned.

The operation cycle level shows that process temperatures are the primary influence on composite properties. The various dwell times, transfer times within the robotic handling system, pressure, and polarization voltage also exert a significant effect on the finished active component.

\section{Conclusions}

Novel manufacturing technologies for thermoplastic composites with tailored embedded piezoceramic modules exhibit considerable potential where the series production of adaptive composite structures for numerous areas of application is concerned. An innovative continuous process chain which enables the fully automated manufacturing of such adaptive composite structures was designed in order to support progress in this field. The resultant process chain comprises specially developed technological devices for specific subprocesses and was physically installed and brought into commission. Detailed process chain modelling was carried out in order to facilitate the analysis, adjustment, and optimization of the entire process chain. Experimental studies of the respective technological devices were used to determine accompanying internal and external interactions between technical and technological properties. The horizontal division of the process chain into subprocesses and its further itemization into vertical levels enabled the 

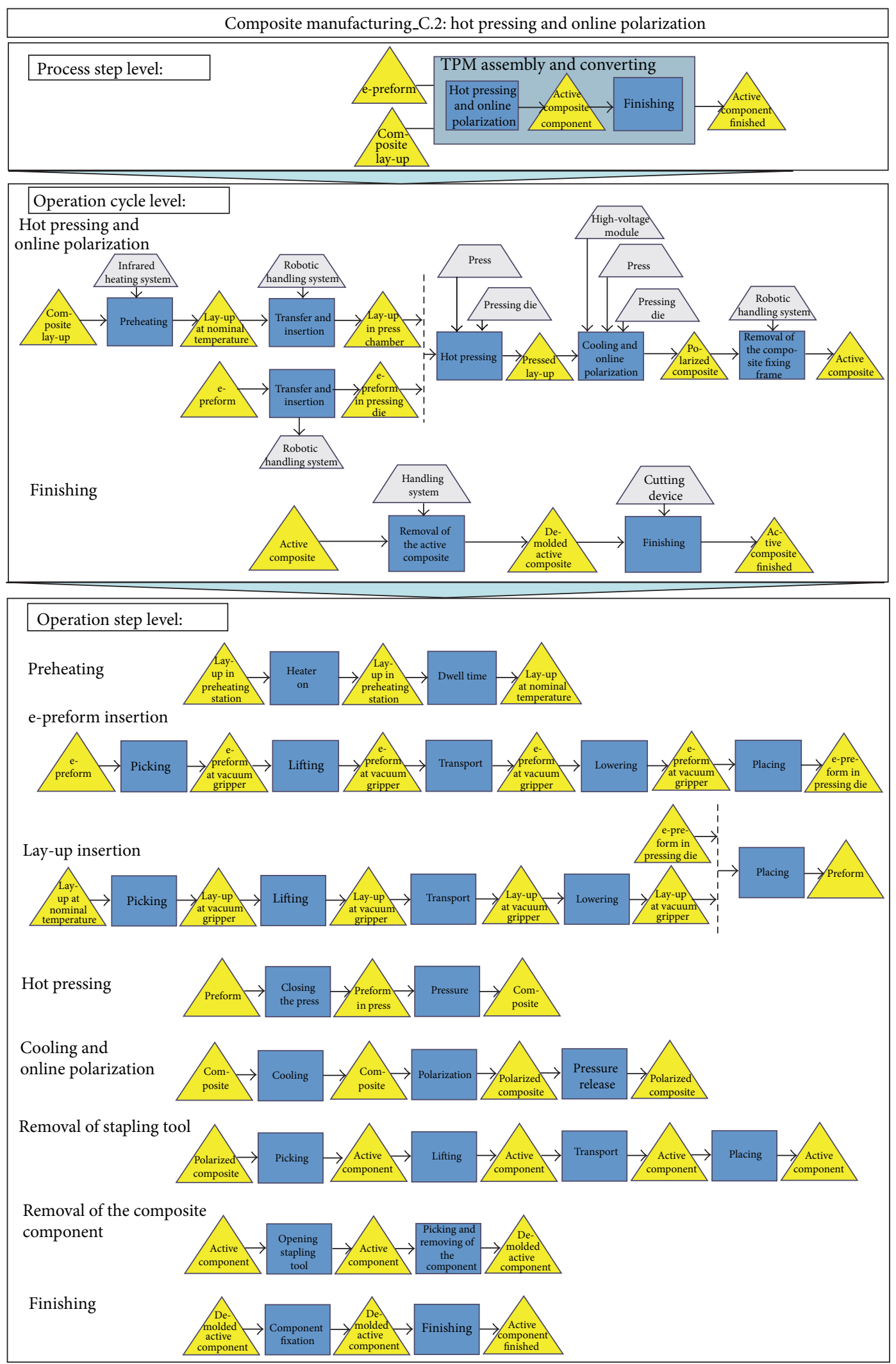

FIGURE 14: Process chain model for hot pressing and online polarization. 


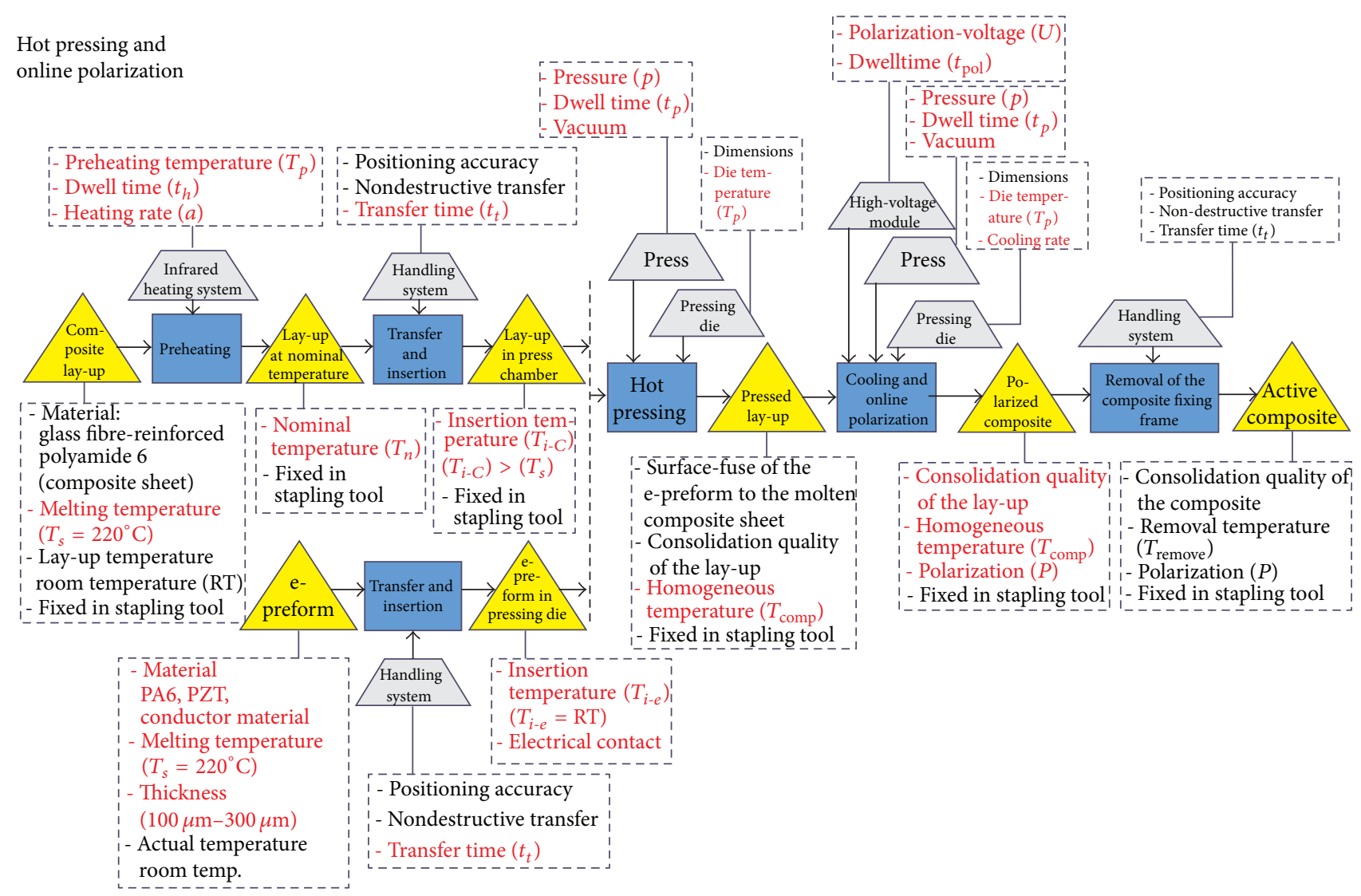

FIGURE 15: Advanced operation cycle level of the consolidation process.

identification and analysis of process-specific interactions in terms of their impact on the respective process result.

In conclusion, the innovative process chain modelled provides a suitable basis for comprehensive process-related analyses. This has been proven by the initial exemplary identification of major interactions. In view of the fact that the primary requirement for thorough and reliable analysis is a very high quantity of process data, future investigations should concentrate on continuative studies based on systematic data recording. This is also a key prerequisite for the identification and analysis of hidden interactions and in turn further process optimization.

\section{Acknowledgments}

This research is supported by the Deutsche Forschungsgemeinschaft (DFG) in context of the Collaborative Research Centre/Transregio 39 PT-PIESA, Subprojects A5 and B4.

\section{References}

[1] E. F. Crawley and J. de Luis, "Use of piezoceramic actuators as elements of intelligent structures," AIAA Journal, vol. 25, no. 10, pp. 1373-1385, 1987.

[2] R. F. Gibson, "A review of recent research on mechanics of multifunctional composite materials and structures," Composite Structures, vol. 92, no. 12, pp. 2793-2810, 2010.
[3] J. Nuffer, T. Pfeiffer, N. Flaschenträger et al., "Piezoelectric composites: application and reliability in adaptronics," in Proceedings of the International Symposium on Piezocomposite Applications, pp. 24-25, Dresden, Germany, September 2009.

[4] S. Adhikari, M. I. Friswell, and D. J. Inman, "Piezoelectric energy harvesting from broadband random vibrations," Smart Materials and Structures, vol. 18, no. 11, Article ID 115005, 7 pages, 2009.

[5] L. Edery-Azulay and H. Abramovich, "Active damping of piezocomposite beams," Composite Structures, vol. 74, no. 4, pp. 458466, 2006.

[6] L. Moro and D. Benasciutti, "Harvested power and sensitivity analysis of vibrating shoe-mounted piezoelectric cantilevers," Smart Materials and Structures, vol. 19, no. 11, Article ID 115011, 12 pages, 2010.

[7] H. Y. Tang, C. Winkelmann, W. Lestari, and V. La Saponara, "Composite structural health monitoring through use of embedded PZT sensors," Journal of Intelligent Material Systems and Structures, vol. 22, no. 8, pp. 739-755, 2011.

[8] S. R. Viswamurthy and R. Ganguli, "Modeling and compensation of piezoceramic actuator hysteresis for helicopter vibration control," Sensors and Actuators A, vol. 135, no. 2, pp. 801-810, 2007.

[9] S. Daynes, P. M. Weaver, and J. A. Trevarthen, "A morphing composite air inlet with multiple stable shapes," Journal of Intelligent Material Systems and Structures, vol. 22, no. 9, pp. 961-973, 2011. 
[10] W. Hufenbach, M. Gude, and A. Czulak, "Actor-initiated snapthrough of unsymmetric composites with multiple deformation states," Journal of Materials Processing Technology, vol. 175, no. 1-3, pp. 225-230, 2006.

[11] M. Gude, Modellierung von faserverstärkten Verbundwerkstoffen und funktionsintegrierenden Leichtbaustrukturen für komplexe Beanspruchungen, Technische Universität Dresden, Habilitation, Dresden, Germany, 2008.

[12] N. Modler, Nachgiebigkeitsmechanismen aus Textilverbunden mit integrierten aktorischen Elementen [Dissertation], Technische Universität Dresden, Dresden, Germany, 2008.

[13] A. F. Arrieta, D. J. Wagg, and S. A. Neild, "Dynamic snapthrough for morphing of bi-stable composite plates," Journal of Intelligent Material Systems and Structures, vol. 22, no. 2, pp. 103-112, 2001.

[14] W. Wilkie, "Method of fabricating a piezoelectric composite apparatus," U.S. Patent No. 6. 629. 341, 2003.

[15] W. Wilkie and R. Bryant, "Piezoelectric macro-fiber composite actuator and manufacturing method," European Patent EP 1983 584 A2, 2008.

[16] R. B. Williams, B. W. Grimsley, D. J. Inman, and W. K. Wilkie, "Manufacturing and cure kinetics modeling for macro fiber composite actuators," Journal of Reinforced Plastics and Composites, vol. 23, no. 16, pp. 1741-1754, 2004.

[17] W. Hufenbach, M. Gude, and T. Heber, "Embedding versus adhesive bonding of adapted piezoceramic modules for function-integrative thermoplastic composite structures," Composites Science and Technology, vol. 71, no. 8, pp. 1132-1137, 2011.

[18] T. Heber, Integrationsgerechte Piezokeramik-Module und großserienfähige Fertigungstechnologien für multifunktionale Thermoplastverbundstrukturen [Dissertation], Technische Universität Dresden, Dresden, Germany, 2011.

[19] W. Hufenbach, M. Gude, and T. Heber, "Design and testing of novel piezoceramic modules for adaptive thermoplastic composite structures," Smart Materials and Structures, vol. 18, no. 4, Article ID 045012, 7 pages, 2009.

[20] W. Hufenbach, M. Gude, N. Modler, T. Heber, A. Winkler, and J. Friedrich, "Processing studies for the development of a robust manufacture process for active composite structures with matrix adapted piezoceramic modules," Composites, vol. 9, no. 2, pp. 133-137, 2009.

[21] W. Hufenbach, M. Gude, N. Modler, T. Heber, and T. Tyczynski, "Sensitivity analysis for the process integrated online polarization of piezoceramic modules in thermoplastic composites," Smart Materials and Structures, vol. 19, no. 10, Article ID 105022, 2010.

[22] U. Scheithauer, M. Flössel, S. Uhlig, A. Schönecker, S. Gebhardt, and A. Michaelis, "Piezokeramische Fasern, Faserkomposite und LTCC-Module zur Integration in Leichtbaustrukturen," in Verbundwerkstoffe: 17. Symposium Verbundwerkstoffe und Werkstoffverbunde, pp. 592-600, Wiley-VCH, New York, NY, USA, 2009.

[23] M. Gude, W. Hufenbach, N. Modler et al., "Process development for high volume manufacture of thermoplastic composites with integrated piezoceramic modules," in Proceedings of the CRC/TR39 3rd Scientific Symposium, pp. 59-64, Chemnitz, Germany, October 2011.

[24] K. Großmann and H. Wiemer, "Reproduzierbare Fertigung in innovativen Prozessketten: Besonderheiten innovativer Prozessketten und methodische Ansätze für ihre Beschreibung, Analyse und Führung (Teil 1)," ZWF-Zeitschrift Für Wirtschaftlichen Fabrikbetrieb, vol. 10, pp. 855-859, 2010. 

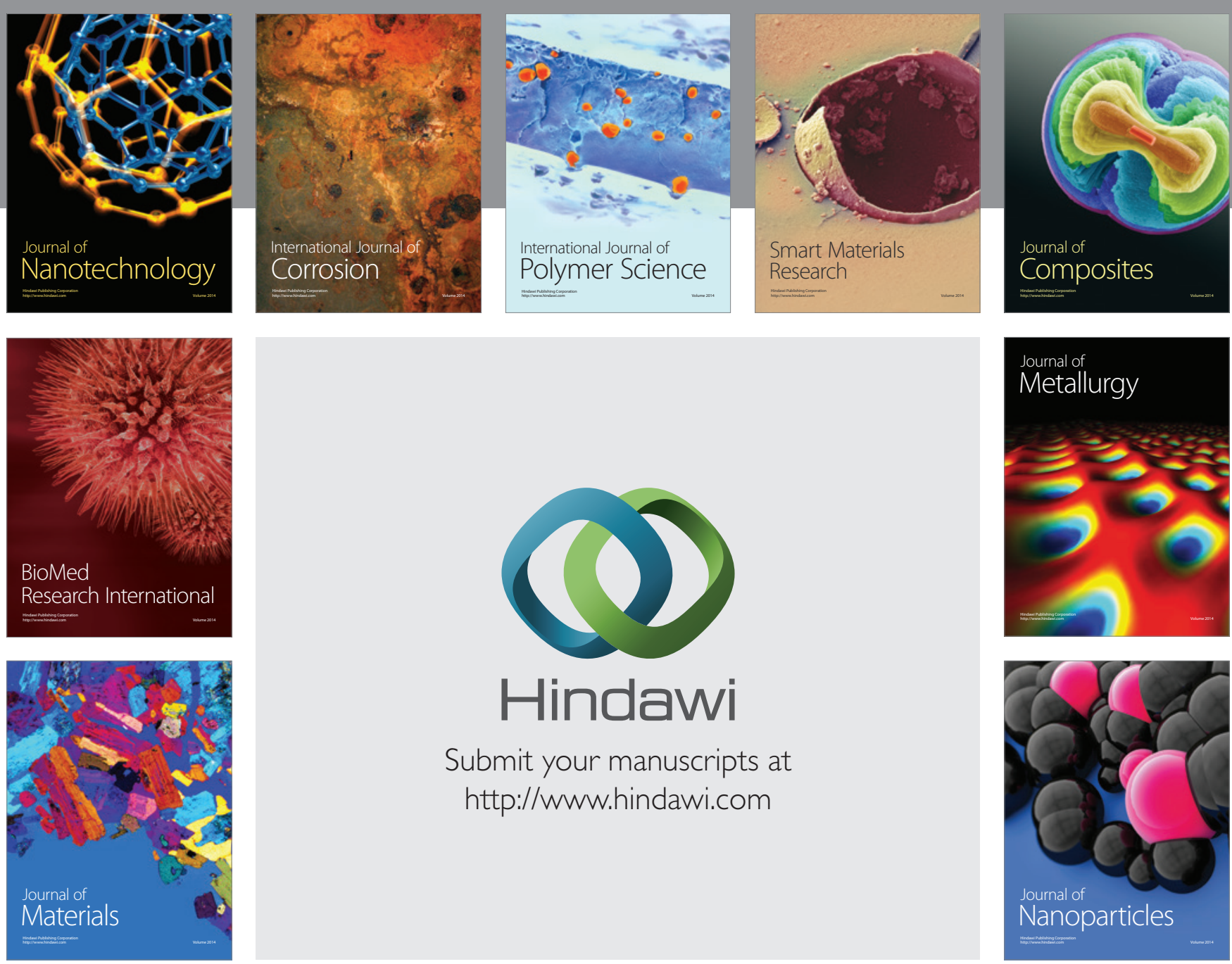

Submit your manuscripts at http://www.hindawi.com
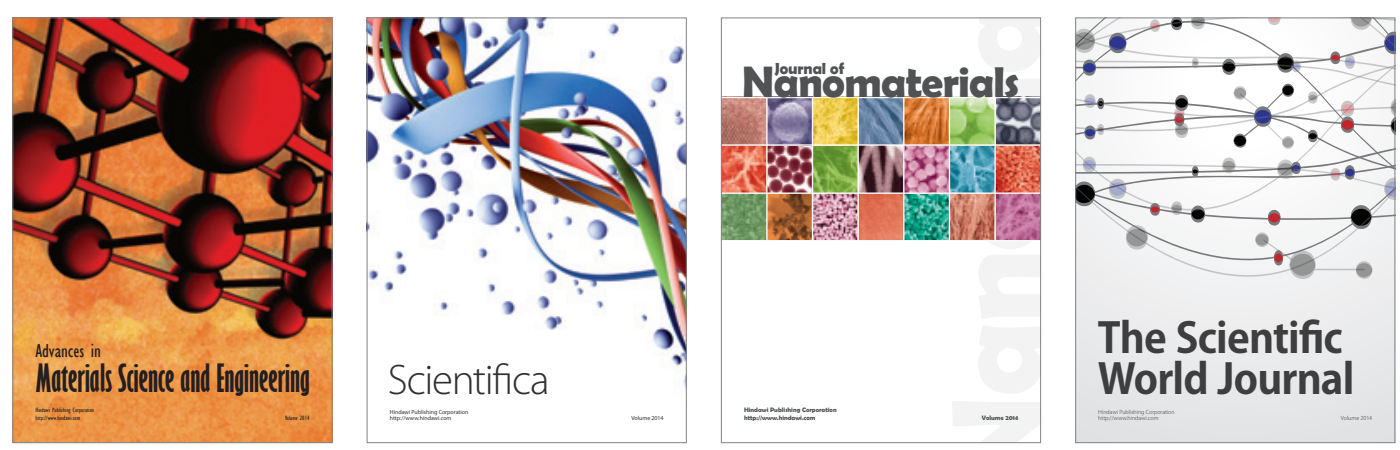

\section{The Scientific World Journal}
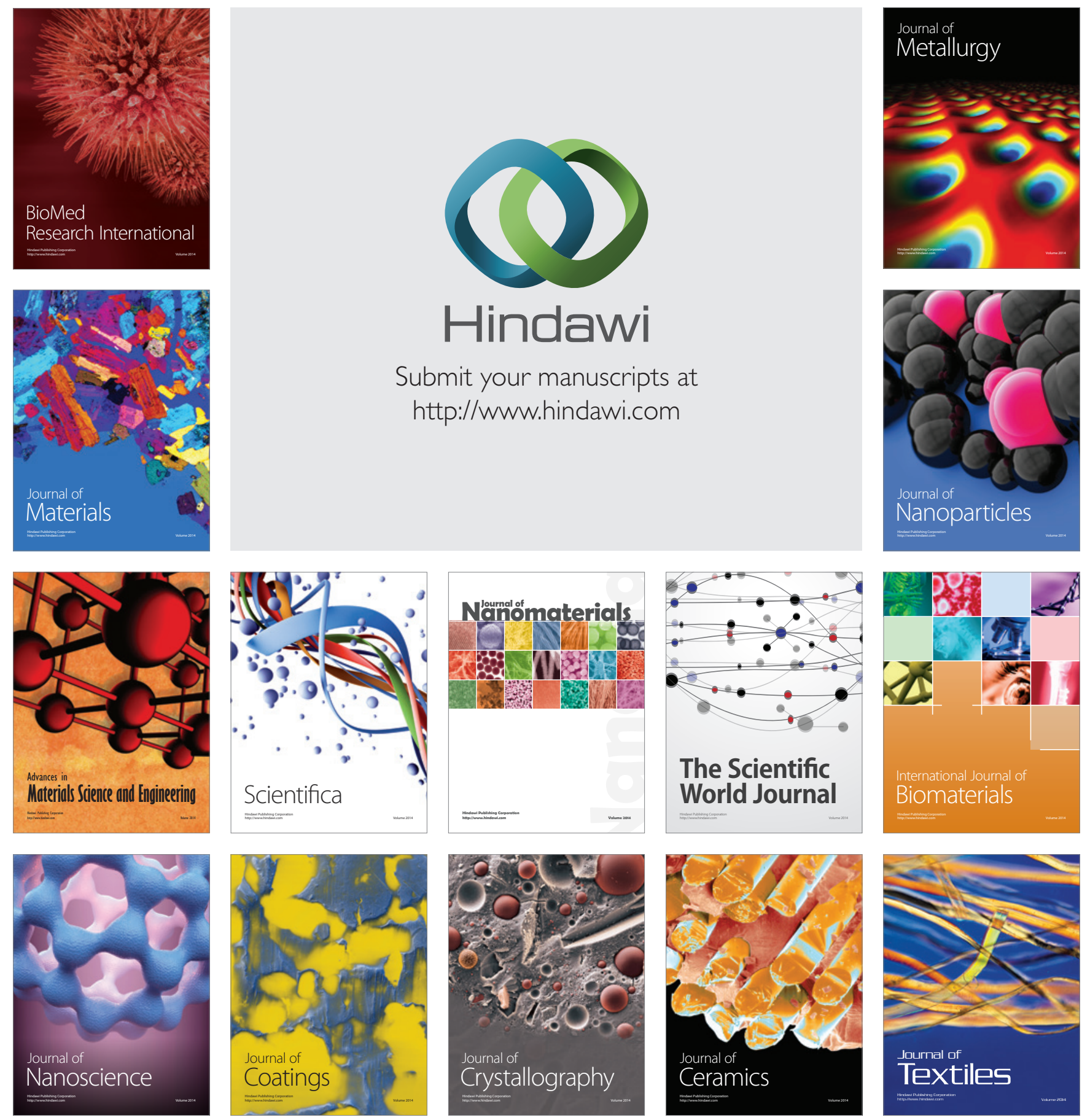